\title{
Manganese Dioxide Supported on Porous Biomorphic Carbons as Hybrid Materials for Energy Storage Devices
}

\author{
Antonio Gutierrez-Pardo ${ }^{\mathrm{a}, \mathrm{b}^{*}}$, Bertrand Lacroix ${ }^{\mathrm{b}}$, Julian Martinez-Fernandez ${ }^{\mathrm{a}, \mathrm{b}}$ Joaquin \\ Ramirez-Rico ${ }^{\mathrm{a}, \mathrm{b}}$. \\ a Departamento Física de la Materia Condensada - ICMS (Universidad de Sevilla-CSIC), \\ Avda. Reina Mercedes S/N, 41012 Seville, Spain. \\ ${ }^{\mathrm{b}}$ Instituto de Ciencia de Materiales de Sevilla (CSIC-Univ. Sevilla), Avda. Américo \\ Vespucio 49, 41092 Seville, Spain. \\ *contact author: agutierrez7@us.es
}

\begin{abstract}
A facile and low-cost method has been employed to fabricate $\mathrm{MnO}_{2} / \mathrm{C}$ hybrid materials for use as binder-free electrodes for supercapacitor applications. Biocarbon monoliths were obtained through pyrolysis of beech wood, replicating the microstructure of the cellulosic precursor, and serve as 3D porous and conductive scaffolds for the direct growth of $\mathrm{MnO}_{2}$ nanosheets by a solution method. Evaluation of the experimental results indicates that a homogeneous and uniform composite material made of a carbon matrix exhibiting ordered hierarchical porosity and $\mathrm{MnO}_{2}$ nanosheets with a layered nanocrystalline structure is obtained. The tuning of the $\mathrm{MnO}_{2}$ content and crystallite size via the concentration of $\mathrm{KMnO}_{4}$ used as impregnation solution allows to obtain composites that exhibit enhanced electrochemical behavior, achieving a capacitance of $592 \mathrm{~F} \cdot \mathrm{g}^{-1}$ in electrodes containing $3 \mathrm{wt} . \% \mathrm{MnO}_{2}$ with an excellent cyclic stability. The electrode materials were characterized before and after electrochemical testing.
\end{abstract}

KEYWORDS: Biomorphic carbons; Manganese oxide; Nanostructured materials; Supercapacitors; Binder-free. 


\section{Introduction}

Energy storage and conversion materials play an essential role in efficient, versatile and eco-environmental use of energy, and are vital for the development of renewable sources of energy as a real alternative to the limited and contaminant nature of fossil fuels. ${ }^{1-2}$ Supercapacitors have emerged as one of the most attractive electrochemical devices with exceptional characteristics featuring high power density, fast charge/discharge capability, long cycling stability and maintenance-free costs. ${ }^{3-5}$ Supercapacitors can be classified into electrochemical double layer capacitors (ELDC), which store energy electrostatically through charge accumulation (non-Faradaic) processes at the interface between the electrode and the electrolyte, and pseudocapacitors, based on fast and reversible redox (Faradaic) reactions in the electrode. ${ }^{3,} 6$ These two mechanisms can act concurrently depending on the characteristics of the electrode material.

The specific capacitance of an EDLC is largely proportional to the surface area of the electrode material accessible to the electrolyte ions. ${ }^{7}$ Carbon-based materials have been the most widely investigated EDLCs and are currently employed in commercial devices due to their physical and chemical properties. ${ }^{5,8}$ Among them, monolithic porous carbon electrodes exhibit benefits when compared to other available forms of carbon owing to their improved electrical conductivity and high permeability and interconnectivity while maintaining mechanical consistency, eliminating the need for conductive additives or binders that can partially block the porosity or decrease the conductivity. ${ }^{10-12}$ Moreover, additional phases can be deposited in the pores of the carbon skeleton to create a hybrid or composite material with improved energy densities over conventional EDLCs. ${ }^{7}$

The development of novel materials that replicate the cellular skeleton of natural structures has been widely studied in materials science. ${ }^{13-14}$ Carbon scaffolds can be obtained by pyrolysis of cellulosic materials, such as wood, retaining the original skeleton of the precursor with open and interconnected hierarchical porosity as well as large pore volume. ${ }^{15-17}$ Through the adequate choice of the precursor and careful pyrolysis control, crack-free monolithic pieces of biocarbon with varied microstructures retaining mechanical integrity can be obtained. 
Conducting polymers ${ }^{18}$ and transition metal oxides/hydroxides ${ }^{19}$ have been usually employed as electroactive materials for supercapacitors. Among them, manganese dioxide $\left(\mathrm{MnO}_{2}\right)$ has received increasing attention since the late $90 \mathrm{~s}^{20}$ due to its exceptional features: low cost, no toxicity, earth abundance and a high specific capacitance $\left(1370 \mathrm{~F} \cdot \mathrm{g}^{-1}\right.$ per manganese atom). ${ }^{21}$ This theoretical value can be achieved only at the nanoscale (in ultrathin films or nanosized particles) due to its poor electrical conductivity. ${ }^{22}$ Nanoscale $\mathrm{MnO}_{2}$ structures need to be incorporated into highly porous and electrically conductive matrices to form composite materials in order to enhance their capabilities and electrochemical performance. ${ }^{21}$

Many chemical and physical methodologies have been developed to prepare nanostructured manganese oxide for electrochemical applications, including methods such as sol-gel, ${ }^{23}$ dip coating, ${ }^{24}$ electrochemical deposition, ${ }^{25}$ or electrostatic spray deposition, ${ }^{26}$ to name a few. Compared to other techniques, solution chemical synthesis methods are a facile and alternative synthetic strategy for the preparation of $\mathrm{MnO}_{2}$ with desirable morphologies and improved performance. ${ }^{27} \mathrm{MnO}_{2}$ nanostructures develop in situ at the external surface of carbon matrices by redox deposition, creating an intimate connection with the conducting carbons. ${ }^{21,28}$

This work aims to exploit the advantages of using biomorphic carbons obtained from pyrolyzed wood as 3D binder-free scaffolds to deposit nanostructured $\mathrm{MnO}_{2}$ by simple immersion in $\mathrm{KMnO}_{4}$ solution, obtaining a self-supported composite material that can be used as supercapacitor electrode.

\section{Experimental}

\subsection{Synthesis of carbon substrates}

Pieces of Beech wood (Fagus sylvatica) were cut into blocks with dimensions ca. (15 x $15 \times 75) \mathrm{mm}^{3}$ and dried in an oven to release adsorbed water from the pores. The pyrolysis process was carried out in a tube furnace with controlled and constant flow of nitrogen. Pyrolysis was performed with a ramp rate of $1^{\circ} \mathrm{C} / \mathrm{min}$ to $500^{\circ} \mathrm{C} ; 5^{\circ} \mathrm{C} / \mathrm{min}$ to maximum temperature (ranging from 850 to $1600^{\circ} \mathrm{C}$ ), soak time of 30 minutes and $5^{\circ} \mathrm{C} / \mathrm{min}$ for cooling down to room temperature. 
Carbon substrates were prepared as $(10 \times 10 \times 1) \mathrm{mm}^{3}$ slabs with a mass of approximately $50 \mathrm{mg}$. These pieces were first cleaned under ultrasounds for 30 minutes in 2:1 ethanol:isopropanol and then washed with deionized water in order to improve the hydrophilicity.

\subsection{Fabrication of $\mathrm{MnO}_{2} /$ biocarbon samples}

Carbon pieces were immersed in a $\mathrm{KMnO}_{4}$ aqueous solution in a glass beaker covered with a watch glass. The beaker was put into an oven and heated at $65^{\circ} \mathrm{C}$ for 5 days, until the purple color of $\mathrm{KMnO}_{4}$ solution disappeared. The $\mathrm{MnO}_{2} / \mathrm{C}$ products were collected, rinsed slightly with water and heated at $100^{\circ} \mathrm{C}$ until complete drying.

A series of $\mathrm{MnO}_{2} / \mathrm{C}$ porous materials were prepared by using biocarbon pyrolized at $1000^{\circ} \mathrm{C}$ as substrate and changing the concentration of $\mathrm{KMnO}_{4}$ aqueous solution from 0.15 to $1 \mathrm{mM}$, resulting in composites to which we will refer to as $\mathrm{MnO}_{2} / \mathrm{bioC} 0.15$, $\mathrm{MnO}_{2} /$ bioC $0.3, \mathrm{MnO}_{2} /$ bioC 0.6 and $\mathrm{MnO}_{2} /$ bioC 1 .

\subsection{Material Characterization}

Characterization of carbon monoliths obtained at different pyrolysis temperatures was carried out prior to $\mathrm{KMnO}_{4}$ impregnation to evaluate their properties. The specific surface area was determined by the BET method based on nitrogen adsorption isotherms using a Micromeritics ASAP 2420 Analyzer, the density of the scaffolds was determined by Helium pycnometry using a Micromeritics Accupyc, bulk electrical resistivity was measured using the four-terminal sensing method with a power supply (Iso-Tech IPS 3202), and residual amounts of nitrogen and hydrogen were determined in a fast combustion furnace using pure oxygen in a LECO-CHNS 932 elemental analyzer.

Morphology of the samples was studied by scanning electron microscopy (SEM, JEOL $6460-L V$ ) operating at $20 \mathrm{kV}$. In order to study the structure of the samples, transmission electron microscopy (TEM) experiments were carried out in bright field (BF) and high-resolution (HRTEM) modes using a FEI Talos F200S microscope operating at an accelerating voltage of $200 \mathrm{kV}$ and equipped with Super-X energydispersive X-ray spectrometry (EDX) system which includes two silicon drift detectors. Local compositional analysis of the samples were also performed by combining high- 
angle annular dark field imaging (HAADF) and EDX acquisitions using the scanning transmission electron microscopy (STEM) mode. The elemental mapping experiments were performed over $100 \times 100$ pixels using a dwell time of $0.2 \mathrm{~s}$, and spatial drift correction. To prepare samples for TEM, the $\mathrm{MnO}_{2} / \mathrm{C}$ piece was immersed in ethanol, the surface was scratched and grinded in an agate mortar. The powder was then ultrasonically dispersed. A drop of this dispersion was deposited on a copper grid with a reticulated amorphous carbon film and allowed to dry.

The crystal structures of the metal oxide deposited on carbons were analyzed by X-ray diffraction (XRD), using a D8 Discover Diffractometer (Bruker) with a $\mathrm{Cu} \mathrm{K}_{\alpha}$ source, at an accelerating voltage of $40 \mathrm{kV}$ and a current of $30 \mathrm{~mA}$. X-Ray photoelectron spectroscopy analysis (XPS) was performed in a Leybold-Hereus LHS-10/20 spectrometer operating with $\mathrm{Al} \mathrm{K}_{\alpha}$ monochromatic radiation at a resolution of $1.00 \mathrm{eV}$ for the general spectrum and $0.05 \mathrm{eV}$ for $M n 2 p$ zone spectrum. The binding energy was calibrated against the carbon 1s line $(284.6 \mathrm{eV})$. Raman spectra were obtained using a LabRAM Horiba Jobin Yvon provided with a confocal microscope, with an excitation wavelength of $532 \mathrm{~nm}$ at ambient conditions in the spectral region between 200 and $1800 \mathrm{~cm}^{-1}$.

Thermogravimetric analyses (TGA) in a flow of $100 \mathrm{ml} \mathrm{min}^{-1}$ atmospheric air using a heating rate of $20^{\circ} \mathrm{C} \mathrm{min}^{-1}$ were carried out in a Thermal Advantage SDT-600. Difference weight in samples between 30 and $600^{\circ} \mathrm{C}$ was used to calculate the $\mathrm{MnO}_{2}$ mass as a weight percentage in relation to the total sample mass.

\subsection{Electrochemical measurements}

The electrochemical measurements of the electrode materials were carried out using a Solartron 1287-A potentiostat, with a 1260A frequency response analyzer, in a threeelectrode setup: prepared samples with dimensions of about $(10 \times 10 \times 1) \mathrm{mm}^{3}$ as a working electrode, an $\mathrm{Ag} / \mathrm{AgCl}$ electrode (saturated with $\mathrm{KCl} 3 \mathrm{M},+0.197 \mathrm{~V}$ vs. $\mathrm{NHE}$ ) as a reference electrode and a Pt bar as a counter electrode, using a neutral aqueous solution of $1 \mathrm{M} \mathrm{Na}_{2} \mathrm{SO}_{4}$ as electrolyte. Electrical connections to the $\mathrm{MnO}_{2} /$ biocarbon electrodes were performed using $\mathrm{Cu}$ wire and silver paste for contacts.

Cyclic voltammetry (CV) experiments were performed using scan rates ranging from 1 to $50 \mathrm{mV} \mathrm{s}^{-1}$, at potentials between -1 and $0 \mathrm{~V}$. Galvanostatic charge/discharge (GCD) 
experiments were performed at a potential between -0.9 and $-0.1 \mathrm{~V}$. Electrochemical impedance spectroscopy measurements were performed at $10 \mathrm{mV}$ amplitude and $0 \mathrm{~V}$ open circuit potential at frequencies in the range $10 \mathrm{mHz}$ to $100 \mathrm{kHz}$. The cyclic stability of the working electrode was also tested for 1000 cycles in GCD experiments at a current density of $0.5 \mathrm{~A} \cdot \mathrm{g}^{-1}$.

Specific capacitance, $C_{s}\left(\mathrm{~F} \mathrm{~g} \mathrm{~g}^{-1}\right)$, was calculated from integration of $\mathrm{CV}$ curves and according to the following equation for GCD curves:

$\mathrm{C}_{\mathrm{s}}=\mathrm{I} \Delta \mathrm{t} /(\mathrm{m} \Delta \mathrm{V})$

where $I$ is the charge/discharge current, $m$ is the mass of active material in the electrode, $\Delta t$ is the discharge time, and $\Delta V$ is the potential drop during the discharge process.

After the electrochemical cycling tests, the material microstructure has been evaluated by TEM and XRD analysis.

\section{Results and discussion}

\subsection{Structural characterization}

A macroporous carbon skeleton replicating the microstructure of the original wood is obtained after the pyrolysis process, consisting of interconnected and aligned channels of a bimodal size distribution. Based on prior results (see Table S1) we chose $1000{ }^{\circ} \mathrm{C}$ as the peak pyrolysis temperature for the fabrication of our carbon substrates because electrical resistivity shows a strong decrease when this temperature is increased (from $10.0 \cdot 10^{-3} \Omega \cdot \mathrm{m}$ at $850^{\circ} \mathrm{C}$ to $4.8 \cdot 10^{-4} \Omega \cdot \mathrm{m}$ at $1000^{\circ} \mathrm{C}$ ). Additionally, the BET surface area decreases from this temperature and up to $1600{ }^{\circ} \mathrm{C}$. Thus, $1000^{\circ} \mathrm{C}$ as the pyrolysis temperature represents a tradeoff between surface area and electrical conductivity of the substrates. We found that if we went to lower temperatures we would be sacrificing electrical conductivity, whereas higher temperatures resulted in only a modest increase in conductivity and lower surface areas and nitrogen contents.

Figure 1.A shows a SEM micrograph of a transversal surface of a carbon scaffold in which open and interconnected porosity is fairly shown. Large pores are grouped together surrounded by the growth rings in which small pores are placed. This cut, perpendicular to the growth direction, has been selected to study the material and to 
deposit the $\mathrm{MnO}_{2}$ layers, although top-view (Fig. 1.B) and cross-section images (Fig. 1.C and 1.D) of a cut inside the sample after impregnation with $\mathrm{KMnO}_{4}$ demonstrate the homogeneous adhesion of manganese oxide structures over the whole sample.

Figure 2 shows SEM images of $\mathrm{MnO}_{2} /$ bioC samples fabricated using different concentrations of $\mathrm{KMnO}_{4}$, at different magnifications. The carbon skeleton is coated by a homogeneous layer of $\mathrm{MnO}_{2}$ nanosheets while retaining its 3D and highly porous structure. $\mathrm{MnO}_{2}$ nanostructures with controlled morphologies grown on carbonaceous substrates are succesfully obtained through a redox reaction between carbon and $\mathrm{MnO}_{4}{ }^{-}$, following the equation $(2):^{29}$

$4 \mathrm{MnO}_{4}^{-}+3 \mathrm{C}+\mathrm{H}_{2} \mathrm{O} \rightarrow 4 \mathrm{MnO}_{2}+\mathrm{CO}_{3}^{2-}+2 \mathrm{HCO}_{3}^{-}$

Carbon acts as a reducing agent and substrate for the heterogeneous nucleation of $\mathrm{MnO}_{2}$. Therefore, the length and the size of $\mathrm{MnO}_{2}$ layers deposited on carbon scaffolds are strongly dependent on the concentration of $\mathrm{KMnO}_{4}$ solution. Uniform $\mathrm{MnO}_{2}$ nanosheets grow larger with the increasing of $\mathrm{KMnO}_{4}$ concentration. When the weight of $\mathrm{KMnO}_{4}$ is relatively high (impregnation with $\mathrm{KMnO}_{4} 0.6$ and $1 \mathrm{mM}$, Fig. $2 \mathrm{E}-\mathrm{H}$ ), biocarbons are coated by a layer of aggregated $\mathrm{MnO}_{2}$ nanosheets and some $\mathrm{MnO}_{2}$ nanosheets self-assembled into nanospheres.

The crystalline structure of samples was studied by XRD. Figure 3.A shows the XRD patterns of the prepared samples. Regarding the biocarbon substrate, there are two broad shoulders located at $2 \theta=26^{\circ}$ and $44^{\circ}$ attributed to short range order of amorphous carbon. For hybrid samples, new peaks matched the standard XRD pattern of birnessite-type $\mathrm{MnO}_{2}$ crystalline phase [pdf 42-1317]. ${ }^{30}$ When increasing the $\mathrm{KMnO}_{4}$ concentration during the fabrication, diffraction peaks corresponding to birnessite $\mathrm{MnO}_{2}$ become wider which indicates that crystallites become smaller. Using the Stokes and Wilson formula ${ }^{31}$ for the $(001)$ and (002) peaks located at $2 \theta$ around $12^{\circ}$ and $25^{\circ}$ respectively, the mean grain size can be roughly estimated for the different $\mathrm{KMnO}_{4}$ concentration, as shown in Fig. 3.B: $14-19 \mathrm{~nm}$ for the $0.15 \mathrm{mM}$ sample, $9-11 \mathrm{~nm}$ for the 0.3 and $0.6 \mathrm{mM}$ samples and $5 \mathrm{~nm}$ for the $1 \mathrm{mM}$ sample. These results are in good agreement with the HRTEM results presented in Fig. S1 of the Supporting Information. Moreover, the diffraction signals from biocarbon decrease relative to the $\mathrm{MnO}_{2}$ signal, indicating the increase of $\mathrm{MnO}_{2}$ content in the material. 
Close-up views of the $\mathrm{MnO}_{2}$ nanosheets formed at different $\mathrm{KMnO}_{4}$ concentrations are presented in Figure 4. As it can be seen on the TEM BF images, the bright and homogeneous contrast of the sheets indicates that they are thin and uniform in thickness. The dark lines visible on the TEM images correspond to the edges of the nanosheets that are approximately oriented perpendicularly to the observation plane. At this scale, the main difference observed between the samples is the density of $\mathrm{MnO}_{2}$ nanosheets, with a significant aggregation at high $\mathrm{KMnO}_{4}$ concentration. The HRTEM image recorded at the edge of a nanosheet $\left(\mathrm{KMnO}_{4}\right.$ concentrations of $\left.0.15 \mathrm{mM}\right)$ shows parallel interatomic planes separated by a distance of $7 \AA$ corresponding to the typical (001) planes of birnessite $\mathrm{MnO}_{2}$ phase (see Fig. S1.A). Figure S1 also reveals the presence of small crystallites within the nanosheets. In agreement with the XRD results, their size is found to decrease as the $\mathrm{KMnO}_{4}$ concentration increases, with typical grain dimension of about $15-18 \mathrm{~nm}, 8-12 \mathrm{~nm}$ and $5 \mathrm{~nm}$ for $\mathrm{KMnO}_{4}$ concentrations of 0.15 $\mathrm{mM}, 0.6$ and $1 \mathrm{mM}$, respectively (as determined on different HRTEM images). The interplanar spacings of $2.5 \AA$ and $2.2 \AA$ measured in the nanograins are consistent with the (110) and (201) birnessite-type $\mathrm{MnO}_{2}$ crystalline phase [pdf 42-1317].

Combining STEM-HAADF imaging with EDX acquisitions provides additional insight on the sample composition at the nanoscale. In Figure S2.A, the EDX spectra integrated across the nanosheets confirm the presence of $\mathrm{Mn}$ and $\mathrm{O}$ elements for samples elaborated with $0.15 \mathrm{mM}$ and $0.6 \mathrm{mM} \mathrm{KMnO}_{4}$ impregnations. The STEM-EDX elemental mapping of the $\mathrm{MnO}_{2} / \mathrm{BioC}$ nanocomposite $\left(\mathrm{KMnO}_{4} 0.15 \mathrm{mM}\right.$ solution) shown in Fig. S2.B confirms the homogeneous deposition of the $\mathrm{MnO}_{2}$ nanosheets on the biocarbon support. On the HAADF images, it is worth mentioning that the nanosheet edges that are oriented perpendicular to the observation plane now appear in bright contrast due to the $\mathrm{Z}$ and thickness sensitivity of the technique. ${ }^{32}$

Hybrid samples were evaluated by XPS in order to determine the Mn oxidation state. Survey spectrum confirms that samples contained the elements $\mathrm{C}, \mathrm{Mn}$ and $\mathrm{O}$. The $\mathrm{Mn}$

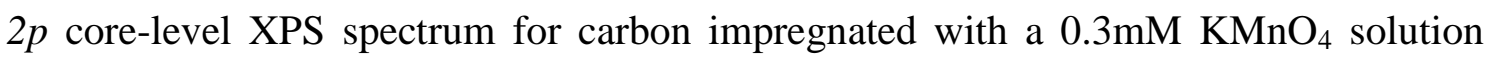
(Figure 5.A) shows an only spin-orbit doublet, attributed to $\mathrm{Mn} 2 \mathrm{p}_{3 / 2}$ and $2 \mathrm{p}_{1 / 2}$ peaks, located at 642.0 and $653.7 \mathrm{eV}$, with a separation of $11.7 \mathrm{eV}$. As expected, these values are in good agreement to the oxidation state $\mathrm{Mn}^{+4}$. 33 
Figure 5.B shows the Raman spectra of samples obtained at different $\mathrm{KMnO}_{4}$ concentration. All samples exhibit bands characteristic of carbonaceous materials: the $\mathrm{G}$ band $\left(1580 \mathrm{~cm}^{-1}, \mathrm{E}_{2 \mathrm{~g}}\right.$ symmetry) represents the vibration of the ideal graphite lattice and the $\mathrm{D}_{1}$ band $\left(1350 \mathrm{~cm}^{-1}, \mathrm{~A}_{1 \mathrm{~g}}\right.$ symmetry) represents the vibration of graphene layer edges. ${ }^{34}$ The latter is the most prominent band in amorphous carbon. The intensity ratio between the $G$ and $D$ bands $\left(\mathrm{I}_{\mathrm{G}} / \mathrm{I}_{\mathrm{D}}\right)$, which informs about the structural degree of ordering on carbon-based materials, was estimated to be $0.20{ }^{15}$ There are no structural modifications in the carbon structure with the impregnation process at $65^{\circ} \mathrm{C}$. The Raman bands of $\mathrm{MnO}_{2}$ are attributed to the $\mathrm{Mn}-\mathrm{O}$ stretching vibration of $\left[\mathrm{MnO}_{6}\right]$ octahedra $\left(501 \mathrm{~cm}^{-1}\right)$, the $\mathrm{Mn}-\mathrm{O}$ stretching vibration in the basal plane of $\left[\mathrm{MnO}_{6}\right]$ sheets $\left(575 \mathrm{~cm}^{-}\right.$ ${ }^{1}$ ) and the symmetric $\mathrm{Mn}-\mathrm{O}$ stretching vibration of $\left[\mathrm{MnO}_{6}\right]$ group $\left(645 \mathrm{~cm}^{-1}\right) .{ }^{35}$ Due to the higher intensity of carbon bands respect to the $\mathrm{MnO}_{2}$ bands, Raman spectra of different samples are shown at a wavenumber between 200 and $1000 \mathrm{~cm}^{-1}$ in order to distinguish the signal from the $\mathrm{MnO}_{2}$ sheets. The band located at $645 \mathrm{~cm}^{-1}$, the most intense, is clearly visible in all samples and becomes stronger with the increasing of $\mathrm{KMnO}_{4}$ concentration, indicating a higher amount of $\mathrm{MnO}_{2}$ in samples, agreeing well with the following TGA results.

Thermogravimetric analysis (Figure S3) was carried out to obtain the composition of the hybrid $\mathrm{MnO}_{2} / \mathrm{C}$ samples, obtaining a weight percent of $\mathrm{MnO}_{2}$ varying from $3.0 \%$ to $20.1 \%$ at a $\mathrm{KMnO}_{4}$ concentrations of 0.15 and $1 \mathrm{mM}$ respectively, calculated from the experimental results between 30 and $600^{\circ} \mathrm{C}$, demonstrating that the $\mathrm{MnO}_{2}$ content increases with the increasing of $\mathrm{KMnO}_{4}$ concentration employed during the fabrication process. Differences in the temperature of carbon combustion can be seen from the TGA graphs, with lower temperatures in composite samples than in the bare carbon, and the lowest combustion temperature is found in sample with the highest content in $\mathrm{MnO}_{2}$, attributed to the catalytic activity of Mn species during this process. ${ }^{36}$

\subsection{Electrochemical behavior}

$\mathrm{MnO}_{2} / \mathrm{C}$ hybrid electrodes were characterized by cyclic voltammetry (CV) and galvanostatic charge/discharge (GCD) experiments at different scan rates and current densities, as well as by electrochemical impedance spectroscopy (EIS). 
Figure 6.A shows the $\mathrm{CV}$ curves of bare biocarbon and prepared $\mathrm{MnO}_{2} /$ bioC sample electrodes. No marked redox peaks were observed in any of the $\mathrm{CV}$, resulting from the almost ideal pseudocapacitive behavior of $\mathrm{MnO}_{2}$ with high reversibility. Figure 6.B shows the galvanostatic charge/discharge curves of different samples, obtaining an almost symmetric shape that reveals a good electrochemical reversibility at a current density of $0.2 \mathrm{~A} / \mathrm{g}$. Since the bare carbon scaffold achieved a maximum of only $7 \mathrm{~F} \mathrm{~g}^{-1}$ at a scan rate of $1 \mathrm{mV} \mathrm{s}^{-1}$, the capacitance of composite samples can be attributed to the $\mathrm{MnO}_{2}$ nanostructures: the carbon skeleton acts mainly as electrical conductive scaffold without significantly contributing to the total capacitance due to its low surface area ${ }^{28}$. Taking account these observations, capacitance values obtained by these techniques have been calculated in relation to the total weight of the electrode and in relation to the $\mathrm{MnO}_{2}$ mass, considered as the active material of the electrode. Based on the total weight of each electrode (Fig. 6.C and D), the specific capacitance increases with the $\mathrm{MnO}_{2}$ content, ascribed to its good pseudocapacitance properties in $\mathrm{Na}_{2} \mathrm{SO}_{4}$ aqueous electrolyte ${ }^{37}$ but the slight reduction of the capacitance in the case of $\mathrm{MnO}_{2} / \mathrm{BioC} 1$ suggests that there is an upper limit to this enhancement and that further increasing the $\mathrm{MnO}_{2}$ load will not result in higher capacities due to the relatively larger size and the formation of aggregates in the $\mathrm{MnO}_{2}$ nanostructures, leading to a poor electrical conductivity of the electrode. If specific capacitance is calculated taking only the mass of active material into account, we observe a decrease with increasing $\mathrm{MnO}_{2}$ content and thus reduced crystallinity. $\mathrm{MnO}_{2} / \mathrm{BioC} 0.15$ shows the largest specific capacitance, $592 \mathrm{~F} \mathrm{~g}^{-1}$ at $1 \mathrm{mV} \mathrm{s}^{-1}$, attributed to the small and thin nanostructures, which increase the contact area with the biocarbon scaffold and enhance the electric transfer, as well as to the higher crystallinity. The capacitance values decrease when the scan rate is increased in all cases, because of part of the surface of the electrode is inaccessible at rapid charging-discharging rates. ${ }^{38}$ A summary of experimental results is included in Table 1.

Electrochemical Impedance Spectroscopy (EIS) measurements were performed and are plotted in Figure S4, along with the fits to the equivalent circuit depicted in Fig. S4's inset. This circuit consists of a constant phase element (CPE) that was chosen to model the frequency dispersion behavior of the capacitive (low frequency) in parallel with a resistor the describes charge-transfer resistance $\left(R_{c t}\right)$, which is itself in series with a Warburg element $W_{s}$ that takes care of the diffusion limited kinetics in the electrolyte. In series with the whole circuit is an equivalent series resistance (ESR). Frequency 
dispersion parameters were in the range $\gamma=0.82-0.87$ for all $\mathrm{MnO}_{2}$ contents (a value of $\gamma=1$ corresponding to the ideal capacitive behavior). ESRs were in the range of $5 \pm 2 \Omega$ but it was highest in the case of the electrode containing the highest $\mathrm{MnO}_{2}$ load, reaching 7.2 $\Omega$. Charge transfer resistances were lowest for the sample containing 3 wt. $\% \mathrm{MnO}_{2}$, suggesting that increasing $\mathrm{MnO}_{2}$ coverage and thickness reduces transfer efficiency.

Since stability to repeated charge-discharge cycles is essential in electrochemical storage devices, we performed a series of tests subjecting the electrodes to 1000 cycles at $0.5 \mathrm{~A} / \mathrm{g}$ current density (calculated using total electrode mass). Results for the sample obtained from a $0.6 \mathrm{mM} \mathrm{KMnO}_{4}$ concentration are shown in Figure 7.A. Clearly, capacitance is retained and after a decrease in the first 100-200 cycles, increases back to $100 \%$ and even higher.

Monolithic electrodes eliminate the need of preparing complex electrode slurries and the use of binders and conductive additives. Consequently, there are no dead volumes in the electrode structure and a large interfacial resistance caused by the binders is avoided, ensuring a better electrochemical use of the active material. A comparison with $\mathrm{MnO}_{2}-\mathrm{C}$ hybrid electrodes presented in the literature is reported in Table 2. When compared to other binder-free electrodes using different form of carbons, we obtain capacitance values very similar in relation to $\mathrm{MnO}_{2}$ mass in the materials, but with better capacity retention. In relation to $\mathrm{MnO}_{2}$ nanostructures deposited using a similar procedure, ${ }^{28,30}$ a capacitance value in the range of these works is obtained without the need of using an additional conductive network.

The microstructural behavior of the electrodes has also been studied after electrochemical cycling. The TEM observation shown in Fig. 7.A points out a significant change in the morphology of manganese oxide after cycling, which is characterized by the removal of the nanosheet nanostructure and the formation of nanoparticles of size ranging from about 20 to $100 \mathrm{~nm}$. According to XRD (Fig. 7.B), a transformation from birnessite-type $\mathrm{MnO}_{2}$ structure to hausmannite $\mathrm{Mn}_{3} \mathrm{O}_{4}$ [pdf 240734] is evidenced. This structural and compositional change has been verified by HRTEM (Fig. S5) and STEM-EDX (Fig. S6) analysis. As shown in Table 3, the quantification of EDX spectra gives us an estimation of the nanostructure composition before and after cycling tests. In the samples before cycling, the nanosheets present an 
$\mathrm{O} / \mathrm{Mn}$ atomic ratio closed to 2 . After cycling, this ratio decreases to about 1.4 in the nanostructures, which confirm the presence of $\mathrm{Mn}_{3} \mathrm{O}_{4}$ nanoparticles.

Some studies report a cyclic stability equal or higher than $100 \%$ even after 5000 cycles in voltammetry using $\mathrm{Na}_{2} \mathrm{SO}_{4}$ as electrolyte (which varies its concentration from 0.1 to $1 \mathrm{M})$ in materials containing $\mathrm{MnO}_{2}$ in different phases: amorphous $\mathrm{MnO}_{2}$ thin films, ${ }^{39}$ pristine- $\mathrm{MnO}_{2}{ }^{40}$ or, as in our case, birnessite- $\mathrm{MnO}_{2} \cdot{ }^{30}$ However, little information about the origin of this unusual phenomenon is given in this case; the authors suggest that regions could be formed in $\mathrm{MnO}_{2}$ nanostructures upon electrochemical cycling due to the repeated insertion/extraction of the electrolyte ions into/out of the $\mathrm{MnO}_{2}$ electrode materials, leading to the increase in specific capacitance with cycling. In the literature we can find some studies about the oxidation of (pure) $\mathrm{Mn}_{3} \mathrm{O}_{4}$ to $\mathrm{MnO}_{2}$ by electrochemical cycling. ${ }^{41-43}$

Our work points out more significant changes after cycling, with morphological and structural modifications of the manganese oxide nanostructures. Although the reduction of $\mathrm{MnO}_{2}$ electrode is known for cycling voltammetry experiments in alkaline media, ${ }^{44}$ our singular observation has to our knowledge never been reported using $\mathrm{Na}_{2} \mathrm{SO}_{4}$ as electrolyte. As a consequence, the exact transformation mechanisms involved upon cycling are still unclear for our system and they will be the subject for further investigations. A possible explanation to our good capacitance stability under cycling may however be found regarding the high specific capacitance of $\mathrm{Mn}_{3} \mathrm{O}_{4}$ nanoparticles / amorphous carbon system recently reported. ${ }^{45}$

\section{Conclusions}

In this work, an easy and low-cost method to prepare hybrid $\mathrm{MnO}_{2} /$ biocarbon materials is presented. The growth of manganese dioxide over the surface of carbon monoliths, resulting from pyrolysis of wood, has been achieved by the reaction between biocarbon and aqueous $\mathrm{KMnO}_{4}$. According to our experimental results this procedure allows to obtain a homogeneous adhesion of $\mathrm{MnO}_{2}$ nanostructures over the whole carbon scaffold. An extensive analysis at the nanoscale points out that the oxide layer is composed of thin nanosheets that exhibit a nanocrystalline birnessite-type $\mathrm{MnO}_{2}$ structure. Changing the fabrication conditions by increasing the $\mathrm{KMnO}_{4}$ concentration 
leads to a higher $\mathrm{MnO}_{2} \%$ wt. content in the final sample and to smaller $\mathrm{MnO}_{2}$ crystallites within the nanosheets.

The capacitance properties of the hybrid materials were measured by electrochemical techniques. The samples showed good rate capacitance performances due to the conductive and hierarchical porous structure of the biocarbon skeleton and the nanostructure of $\mathrm{MnO}_{2}$, obtaining a self-supported material that can be employed as binder-free electrode for energy storage applications. A specific capacitance of $592 \mathrm{~F} \mathrm{~g}^{-1}$ for a sample with $3 \%$ wt. content in $\mathrm{MnO}_{2}$ was obtained, a promising value in the range of related $\mathrm{MnO}_{2} / \mathrm{C}$ hybrid materials. This optimal capacitance value is attributed to the hybrid material that combines small and thin nanostructures with higher crystallinity. Moreover, an excellent cyclic stability of the materials with the cumulative use has been obtained. Interestingly, the study of the electrodes microstructure after electrochemical cycling showed morphological and structural modifications of the manganese oxide nanostructures that will be the subject for further investigations.

\section{Associated content}

Carbon characterization, TGA, and HRTEM and STEM-EDX before and after electrochemical testing are available in the Supporting Information.

\section{Acknowledgements}

This work was supported by the Junta de Andalucía under grant PE2012-TEP862 as well as the Spanish Ministerio de Economía y Competitividad under the Retos grant scheme (MAT2013-41233-R). A. Gutiérrez-Pardo and B. Lacroix are grateful to the Junta de Andalucía for their postdoctoral grants. Elemental analysis, electron microscopy, X-ray diffraction, XPS, thermogravimetric analysis and electrochemical measurements were performed at the CITIUS central services of the University of Seville. Raman scattering measurements were performed at the ICMS (University of Seville-CSIC).

\section{References}

1. Liu, C.; Li, F.; Ma, L.-P.; Cheng, H.-M. Advanced Materials for Energy Storage. Adv. Mater. 2010, 22, E28-E62. 
2. Arico, A. S.; Bruce, P.; Scrosati, B.; Tarascon, J.-M.; van Schalkwijk, W. Nanostructured Materials for Advanced Energy Conversion and Storage Devices. Nat. Mater. 2005, 4, 366-377.

3. Wang, G.; Zhang, L.; Zhang, J. A Review of Electrode Materials for Electrochemical Supercapacitors. Chem. Soc. Rev. 2012, 41, 797-828.

4. Guo, Y.-G.; Hu, J.-S.; Wan, L.-J. Nanostructured Materials for Electrochemical Energy Conversion and Storage Devices. Adv. Mater. 2008, 20, 2878-2887.

5. Burke, A. Ultracapacitors: Why, How, and Where is the Technology. J. Power Sources 2000, 91, 37-50.

6. Simon, P.; Gogotsi, Y. Materials for Electrochemical Capacitors. Nat. Mater. 2008, 7, 845-854.

7. Zhang, L. L.; Zhao, X. S. Carbon-based Materials as Supercapacitor Electrodes. Chem. Soc. Rev. 2009, 38, 2520-2531.

8. Frackowiak, E.; Béguin, F., Carbon Materials for the Electrochemical Storage of Energy in Capacitors. Carbon 2001, 39, 937-950.

9. Candelaria, S. L.; Shao, Y.; Zhou, W.; Li, X.; Xiao, J.; Zhang, J.-G.; Wang, Y.; Liu, J.; Li, J.; Cao, G. Nanostructured Carbon for Energy Storage and Conversion. Nano Energy 2012, 1, 195-220.

10. Ruiz, V.; Blanco, C.; Santamaría, R.; Ramos-Fernández, J. M.; Martínez-Escandell, M.; Sepúlveda-Escribano, A.; Rodríguez-Reinoso, F. An Activated Carbon Monolith as an Electrode Material for Supercapacitors. Carbon 2009, 47, 195-200.

11. Sevilla, M.; Fuertes, A. B. Fabrication of Porous Carbon Monoliths with a Graphitic Framework. Carbon 2013, 56, 155-166.

12. Liu, M.-C.; Kong, L.-B.; Zhang, P.; Luo, Y.-C.; Kang, L. Porous Wood Carbon Monolith for High-Performance Supercapacitors. Electrochim. Acta 2012, 60, 443-448.

13. Greil, P. Biomorphous Ceramics from Lignocellulosics. J. Eur. Ceram. Soc. 2001, $21,105-118$.

14. Wu, S.; Liu, X.; Yeung, K. W. K.; Liu, C.; Yang, X. Biomimetic Porous Scaffolds for Bone Tissue Engineering. Mater. Sci. Eng., R 2014, 80, 1-36.

15. Gutiérrez-Pardo, A.; Ramírez-Rico, J.; Arellano-López, A. R.; Martínez-Fernández, J. Characterization of Porous Graphitic Monoliths from Pyrolyzed Wood. J. Mater. Sci. 2014, 49, 7688-7696.

16. Byrne, E. C.; Nagle, C. D. Cellulose Derived Composites - A New Method for Materials Processing. Mater. Res. Innovations 2014, 1, 137-144.

17. Byrne, C. E.; Nagle, D. C. Carbonization of Wood for Advanced Materials Applications. Carbon 1997, 35, 259-266.

18. Snook, G. A.; Kao, P.; Best, A. S. Conducting-Polymer-Based Supercapacitor Devices and Electrodes. J. Power Sources 2011, 196, 1-12. 
19. Lokhande, C. D.; Dubal, D. P.; Joo, O.-S. Metal Oxide Thin Film Based Supercapacitors. Curr. Appl. Phys. 2011, 11, 255-270.

20. Lee, H. Y.; Goodenough, J. B. Supercapacitor Behavior with KCl Electrolyte. J. Solid State Chem. 1999, 144, 220-223.

21. Wang, J.-G.; Kang, F.; Wei, B. Engineering of $\mathrm{MnO}_{2}$-Based Nanocomposites for High-performance Supercapacitors. Prog. Mater. Sci. 2015, 74, 51-124.

22. Lee, S. W.; Kim, J.; Chen, S.; Hammond, P. T.; Shao-Horn, Y. Carbon Nanotube/Manganese Oxide Ultrathin Film Electrodes for Electrochemical Capacitors. ACS Nano 2010, 4, 3889-3896.

23. Pang, S. C.; Anderson, M. A.; Chapman, T. W. Novel Electrode Materials for Thin-Film Ultracapacitors: Comparison of Electrochemical Properties of Sol-Gel-Derived and Electrodeposited Manganese Dioxide. J. Electrochem. Soc. 2000, 147, 444-450.

24. Chin, S.-F.; Pang, S.-C.; Anderson, M. A. Material and Electrochemical Characterization of Tetrapropylammonium Manganese Oxide Thin Films as Novel Electrode Materials for Electrochemical Capacitors. J. Electrochem. Soc. 2002, 149, A379-A384.

25. Xue, T.; Xu, C.-L.; Zhao, D.-D.; Li, X.-H.; Li, H.-L. Electrodeposition of Mesoporous Manganese Dioxide Supercapacitor Electrodes through Self-Assembled Triblock Copolymer Templates. J. Power Sources 2007, 164, 953-958.

26. Djurfors, B.; Broughton, J. N.; Brett, M. J.; Ivey, D. G. Production of Capacitive Films from Mn Thin Films: Effects of Current Density and Film Thickness. J. Power Sources 2006, 156, 741-747.

27. Xia, X.; Zhang, Y.; Chao, D.; Guan, C.; Zhang, Y.; Li, L.; Ge, X.; Bacho, I. M.; Tu, J.; Fan, H. J. Solution Synthesis of Metal Oxides for Electrochemical Energy Storage Applications. Nanoscale 2014, 6, 5008-5048.

28. He, S.; Hu, C.; Hou, H.; Chen, W. Ultrathin $\mathrm{MnO}_{2}$ Nanosheets Supported on Cellulose Based Carbon Papers for High-Power Supercapacitors. J. Power Sources 2014, 246, 754-761.

29. Lei, Z.; Shi, F.; Lu, L. Incorporation of $\mathrm{MnO}_{2}$-Coated Carbon Nanotubes between Graphene Sheets as Supercapacitor Electrode. ACS Appl. Mater. Interfaces 2012, 4, 1058-1064.

30. He, S.; Chen, W. High Performance Supercapacitors Based on Three-Dimensional Ultralight Flexible Manganese Oxide Nanosheets/Carbon Foam Composites. J. Power Sources 2014, 262, 391-400.

31. Stokes, A. R.; Wilson, A. J. C. A Method of Calculating the Integral Breadths of Debye-Scherrer Lines. Math. Proc. Cambridge Philos. Soc. 1942, 38, 313-322.

32. Nellist, P. D.; Pennycook, S. J. The Principles and Interpretation of Annular DarkField Z-Contrast Imaging. Adv. Imaging and Electron Phys. 2000, 113, 147-203. 
33. Li, G.-R.; Feng, Z.-P.; Ou, Y.-N.; Wu, D.; Fu, R.; Tong, Y.-X. Mesoporous $\mathrm{MnO}_{2} /$ Carbon Aerogel Composites as Promising Electrode Materials for HighPerformance Supercapacitors. Langmuir 2010, 26, 2209-2213.

34. Sadezky, A.; Muckenhuber, H.; Grothe, H.; Niessner, R.; Pöschl, U. Raman Microspectroscopy of Soot and Related Carbonaceous Materials: Spectral Analysis and Structural Information. Carbon 2005, 43, 1731-1742.

35. Buciuman, F.; Patcas, F.; Craciun, R.; R. T. Zahn, D. Vibrational Spectroscopy of Bulk and Supported Manganese Oxides. Phys. Chem. Chem. Phys. 1999, 1, 185-190.

36. Wang, J.-G.; Yang, Y.; Huang, Z.-H.; Kang, F. Effect of Temperature on the Pseudo-Capacitive Behavior of Freestanding $\mathrm{MnO}_{2} @$ Carbon Nanofibers Composites Electrodes in Mild Electrolyte. J. Power Sources 2013, 224, 86-92.

37. Toupin, M.; Brousse, T.; Bélanger, D. Influence of Microstucture on the Charge Storage Properties of Chemically Synthesized Manganese Dioxide. Chem. Mater. 2002, 14, 3946-3952.

38. Pandolfo, A. G.; Hollenkamp, A. F. Carbon Properties and their Role in Supercapacitors. J. Power Sources 2006, 157, 11-27.

39. Lu, X.; Zhai, T.; Zhang, X.; Shen, Y.; Yuan, L.; Hu, B.; Gong, L.; Chen, J.; Gao, Y.; Zhou, J.; Tong, Y.; Wang, Z. L. WO3-x@Au@MnO2 Core-Shell Nanowires on Carbon Fabric for High-Performance Flexible Supercapacitors. Adv. Mater. 2012, 24, 938-944.

40. Ye, K.-H.; Liu, Z.-Q.; Xu, C.-W.; Li, N.; Chen, Y.-B.; Su, Y.-Z. $\mathrm{MnO}_{2} /$ Reduced Graphene Oxide Composite as High-Performance Electrode for Flexible Supercapacitors. Inorg. Chem. Commun. 2013, 30, 1-4.

41. Dubal, D. P.; Dhawale, D. S.; Salunkhe, R. R.; Lokhande, C. D. Conversion of Chemically Prepared Interlocked Cubelike $\mathrm{Mn}_{3} \mathrm{O}_{4}$ to Birnessite $\mathrm{MnO}_{2}$ Using Electrochemical Cycling. J. Electrochem. Soc. 2010, 157, A812-A817.

42. Dai, Y.; Wang, K.; Xie, J. From Spinel $\mathrm{Mn}_{3} \mathrm{O}_{4}$ to Layered Nanoarchitectures using Electrochemical Cycling and the Distinctive Pseudocapacitive Behavior. Appl. Phys. Lett. 2007, 90, 104102.

43. Nam, K.-W.; Kim, K.-B. Manganese Oxide Film Electrodes Prepared by Electrostatic Spray Deposition for Electrochemical Capacitors. J. Electrochem. Soc. 2006, 153, A81-A88.

44. Donne, S. W.; Lawrance, G. A.; Swinkels, D. A. J. Redox Processes at the Manganese Dioxide Electrode: III. Detection of Soluble and Solid Intermediates during Reduction. J. Electrochem. Soc. 1997, 144, 2961-2967.

45. Nagamuthu, S.; Vijayakumar, S.; Muralidharan, G. Synthesis of $\mathrm{Mn}_{3} \mathrm{O}_{4} /$ Amorphous Carbon Nanoparticles as Electrode Material for High Performance Supercapacitor Applications. Energy Fuels 2013, 27, 3508-3515. 
46. Kang, Y. J.; Kim, B.; Chung, H.; Kim, W. Fabrication and Characterization of Flexible and High Capacitance Supercapacitors Based on $\mathrm{MnO}_{2} / \mathrm{CNT} /$ papers. Synth. Met. 2010, 160, 2510-2514.

47. Amade, R.; Jover, E.; Caglar, B.; Mutlu, T.; Bertran, E. Optimization of $\mathrm{MnO}_{2} /$ Vertically Aligned Carbon Nanotube Composite for Supercapacitor Application. J. Power Sources 2011, 196, 5779-5783.

48. Fan, Z.; Chen, J.; Wang, M.; Cui, K.; Zhou, H.; Kuang, Y. Preparation and Characterization of Manganese Oxide/CNT Composites as Supercapacitive Materials. Diamond Relat. Mater. 2006, 15, 1478-1483.

49. Li, Z.; Wang, J.; Liu, X.; Liu, S.; Ou, J.; Yang, S. Electrostatic Layer-by-Layer SelfAssembly Multilayer Films Based on Graphene and Manganese Dioxide Sheets as Novel Electrode Materials for Supercapacitors. J. Mater. Chem. 2011, 2, 3397-3403.

50. Wang, J.-G.; Yang, Y.; Huang, Z.-H.; Kang, F. Coaxial Carbon Nanofibers/ $\mathrm{MnO}_{2}$ Nanocomposites as Freestanding Electrodes for High-Performance Electrochemical Capacitors. Electrochim. Acta 2011, 56, 9240-9247.

51. Huang, Y.; Li, Y.; Hu, Z.; Wei, G.; Guo, J.; Liu, J. A Carbon Modified $\mathrm{MnO}_{2}$ Nanosheet Array as a Stable High-Capacitance Supercapacitor Electrode. J. Mater. Chem. A 2013, 1, 9809-9813. 
Table 1. Most relevant results obtained by electrochemical measurements included in this work, in relation to total mass of each electrode and to the $\mathrm{MnO}_{2}$ mass determined by TGA measurements.

\begin{tabular}{|c|c|c|c|c|c|c|c|c|c|}
\hline & \multicolumn{9}{|c|}{$\left[\mathrm{KMnO}_{4}\right](\mathrm{mM})$} \\
\hline & $\mathbf{0}$ & \multicolumn{2}{|c|}{0.15} & \multicolumn{2}{|c|}{0.3} & \multicolumn{2}{|c|}{0.6} & \multicolumn{2}{|c|}{1.0} \\
\hline & $\begin{array}{c}\text { Total } \\
\text { weight }\end{array}$ & $\begin{array}{c}\text { Total } \\
\text { weight }\end{array}$ & $\begin{array}{c}\mathrm{MnO}_{2} \\
\text { mass }\end{array}$ & $\begin{array}{c}\text { Total } \\
\text { weight }\end{array}$ & $\begin{array}{c}\mathrm{MnO}_{2} \\
\text { mass }\end{array}$ & $\begin{array}{c}\text { Total } \\
\text { weight }\end{array}$ & $\begin{array}{c}\mathrm{MnO}_{2} \\
\text { mass }\end{array}$ & $\begin{array}{c}\text { Total } \\
\text { weight }\end{array}$ & $\begin{array}{c}\mathrm{MnO}_{2} \\
\text { mass }\end{array}$ \\
\hline $\begin{array}{l}\text { Capacitance } \\
\text { at } 1 \mathrm{mV} \mathrm{s}^{-1} \\
\left(\mathrm{~F} \cdot \mathrm{g}^{-1}\right)\end{array}$ & 7.1 & 18 & 592 & 26 & 448 & 67 & 381 & 58 & 289 \\
\hline $\begin{array}{l}\text { Capacitance } \\
\text { at } 10 \mathrm{mV} \mathrm{s} \\
{ }^{-1}\left(\mathrm{~F} \cdot \mathrm{g}^{-1}\right)\end{array}$ & 3.4 & 5.7 & 190 & 10 & 174 & 29 & 165 & 24 & 121 \\
\hline $\begin{array}{l}\text { Capacitance } \\
\text { at } 20 \mathrm{~mA} \mathrm{~g}^{-} \\
{ }^{1}\left(\mathrm{~F} \cdot \mathrm{g}^{-1}\right)\end{array}$ & - & 5.0 & 166 & 13 & 224 & 62 & 352 & 58 & 289 \\
\hline $\begin{array}{l}\text { Capacitance } \\
\text { at } 0.2 \mathrm{~A} \mathrm{~g}^{-1} \\
\left(\mathrm{~F} \cdot \mathrm{g}^{-1}\right)\end{array}$ & - & 0.62 & 21 & 2.8 & 48 & 24 & 136 & 19 & 95 \\
\hline
\end{tabular}


Table 2. Capacitive performance of binder-free $\mathrm{MnO}_{2} /$ carbon hybrid electrodes presented in this work and in other research works, in relation to $\mathrm{MnO}_{2}$ mass.

\begin{tabular}{|c|c|c|c|}
\hline Electrode structure & $C_{\text {máx }}\left(F \cdot g^{-1}\right)$ & $\begin{array}{l}\text { Measurement } \\
\text { conditions }\end{array}$ & Stability (\%) \\
\hline Flexible $\mathrm{MnO}_{2} / \mathrm{CNT} /$ paper $^{46}$ & 540 & $2 \mathrm{mV} / \mathrm{s}$ in $\mathrm{CV}$ & 95 \\
\hline $\mathrm{MnO}_{2} / \mathrm{CNTA}^{47}$ & 642 & $10 \mathrm{mV} / \mathrm{s}$ in $\mathrm{CV}$ & 70 \\
\hline $\mathrm{MnO}_{2} / \mathrm{CNT}^{48}$ & 568 & $1 \mathrm{~mA} / \mathrm{cm}^{2}$ in $\mathrm{GCD}$ & 88 \\
\hline $\mathrm{MnO}_{2} /$ graphene sheets $^{49}$ & 263 & $0.28 \mathrm{~A} / \mathrm{g}$ in $\mathrm{GCD}$ & 90 \\
\hline $\begin{array}{c}\text { Mesoporous } \mathrm{MnO}_{2} / \text { carbon } \\
\text { aerogel }\end{array}$ & 516 & $2 \mathrm{mV} / \mathrm{s}$ in $\mathrm{CV}$ & 97 \\
\hline $\begin{array}{c}\text { Coaxial carbon } \\
\text { nanofibers } / \mathrm{MnO}_{2}{ }^{50}\end{array}$ & 547 & $1 \mathrm{~A} / \mathrm{g}$ & 94 \\
\hline $\mathrm{MnO}_{2} @ \mathrm{C}$ array on Ti foil ${ }^{51}$ & 587 & $1 \mathrm{~mA} / \mathrm{cm}^{2}$ in $\mathrm{GCD}$ & 94 \\
\hline $\begin{array}{l}\mathrm{MnO}_{2} / \text { carbon paper on } \mathrm{Ni} \\
\text { foam }^{28}\end{array}$ & 307 & $0.5 \mathrm{~A} / \mathrm{g}$ in $\mathrm{GCD}$ & 97 \\
\hline $\begin{array}{l}\mathrm{MnO}_{2} / \text { carbon foam on } \mathrm{Ni} \\
\text { foam }^{30}\end{array}$ & 1270 & $0.5 \mathrm{~A} / \mathrm{g}$ in $\mathrm{GCD}$ & 108 \\
\hline $\begin{array}{c}\mathrm{MnO}_{2} / \text { porous bioCarbon } \\
\text { (This work) }\end{array}$ & 592 & $1 \mathrm{mV} / \mathrm{s}$ in $\mathrm{CV}$ & 106 \\
\hline
\end{tabular}

Table 3. Composition of the nanostructures determined by STEM-EDX for the samples obtained at 0.15 and $0.6 \mathrm{mM} \mathrm{KMnO}_{4}$ concentration. The composition of the nanosheets obtained before GCD measurements has been obtained by scanning a 200x200 nm ${ }^{2}$ area. The composition of the nanostructures formed after GCD measurements for the $0.6 \mathrm{mM}$ sample has been determined by averaging point STEM-EDX measurements across various nanoparticles.

\begin{tabular}{|c|c|c|c|c|c|c|}
\hline \multirow[t]{2}{*}{ Sample } & \multicolumn{4}{|c|}{ Composition of nanostructures (at. \%) } & \multirow{2}{*}{$\begin{array}{c}\mathrm{O} / \mathrm{Mn} \\
\text { ratio }\end{array}$} & \multirow{2}{*}{$\begin{array}{c}\text { Type } \\
\text { ofnanostructure }\end{array}$} \\
\hline & Mn & $\mathbf{O}$ & $\mathbf{K}$ & $\mathbf{S i}$ & & \\
\hline $\mathrm{MnO}_{2} /$ bioC 0.15 & $33 \pm 1$ & $62 \pm 1$ & $3.0 \pm 0.1$ & $2.0 \pm 0.1$ & $1.9 \pm 0.1$ & Nanosheet \\
\hline $\mathrm{MnO}_{2} / \mathrm{bioC} 0.6$ & $29 \pm 1$ & $66 \pm 1$ & $2.0 \pm 0.1$ & $3.0 \pm 0.1$ & $2.3 \pm 0.2$ & Nanosheet \\
\hline $\begin{array}{c}\mathrm{MnO}_{2} / \text { bioC } 0.6 \text { after } \\
\text { GCD }\end{array}$ & $40 \pm 2$ & $57 \pm 2$ & 0 & $3 \pm 2$ & $1.4 \pm 0.1$ & Nanoparticle \\
\hline
\end{tabular}



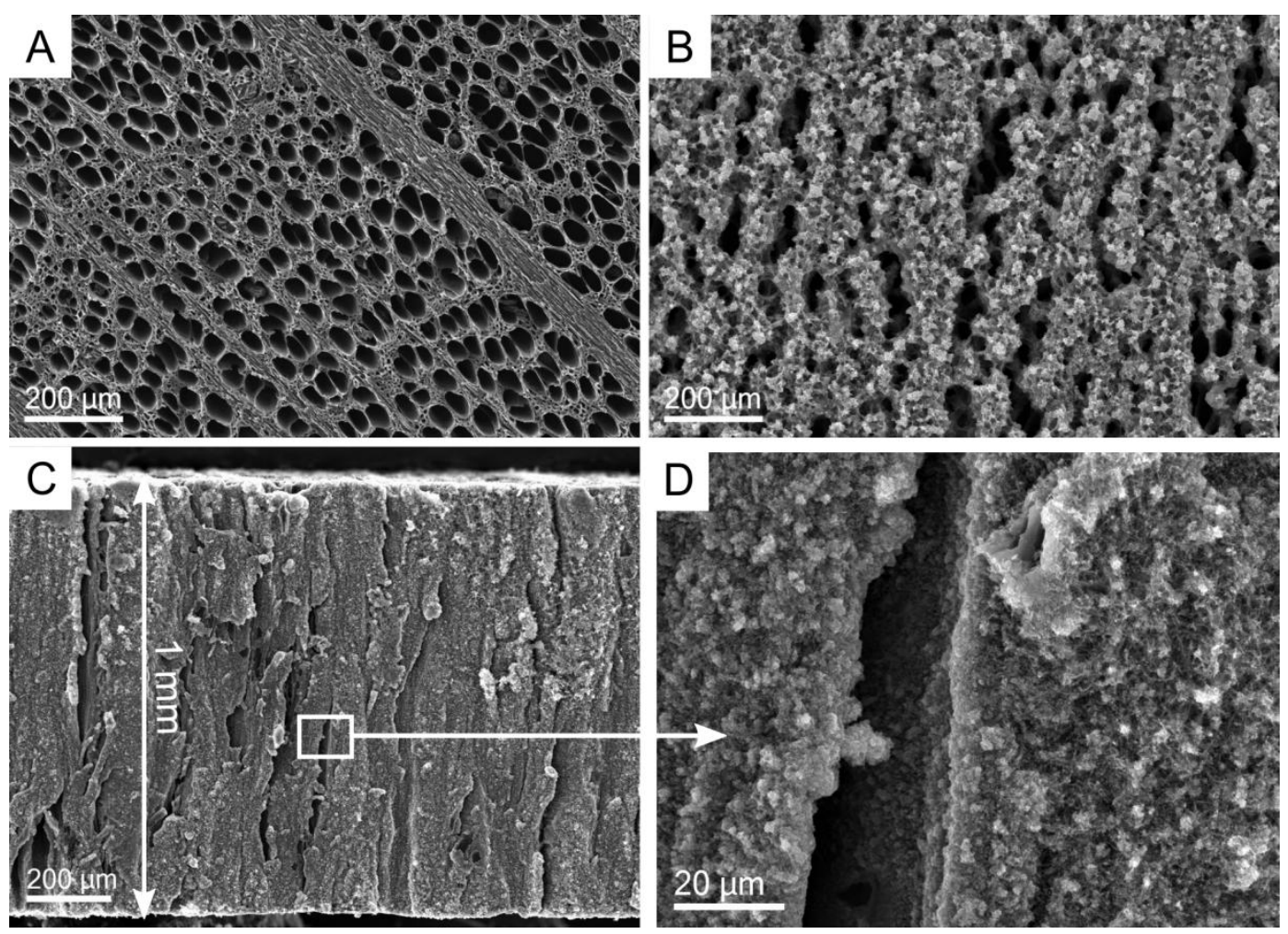

Figure 1. Representative SEM micrographs (BSE images) of the (A) biocarbon obtained from pyrolysis (B) $\mathrm{MnO}_{2}$ /bioC in top view, (C) cross section and (D) selected area from 1.C after impregnation of $\mathrm{KMnO}_{4} \quad 0.3 \mathrm{mM}$, representative of all concentrations studied. 

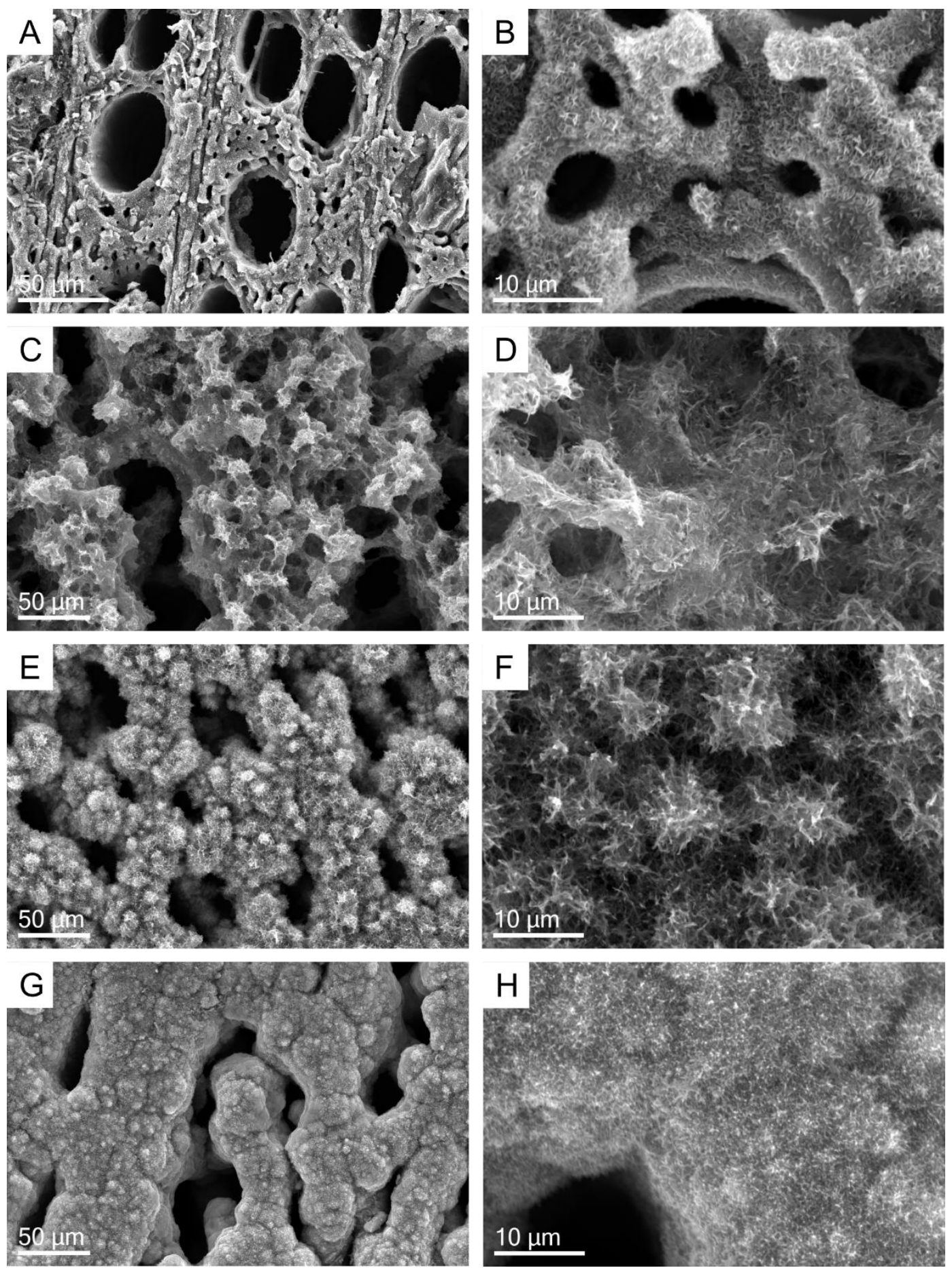

Figure 2. SEM images of $\mathrm{MnO}_{2} /$ bioC samples using different concentrations of $\mathrm{KMnO}_{4}$ solution (A, B) $0.15 \mathrm{mM},(\mathrm{C}, \mathrm{D}) 0.3 \mathrm{mM}$, (E, F) $0.6 \mathrm{mM},(\mathrm{G}, \mathrm{H}) 1 \mathrm{mM}$. 


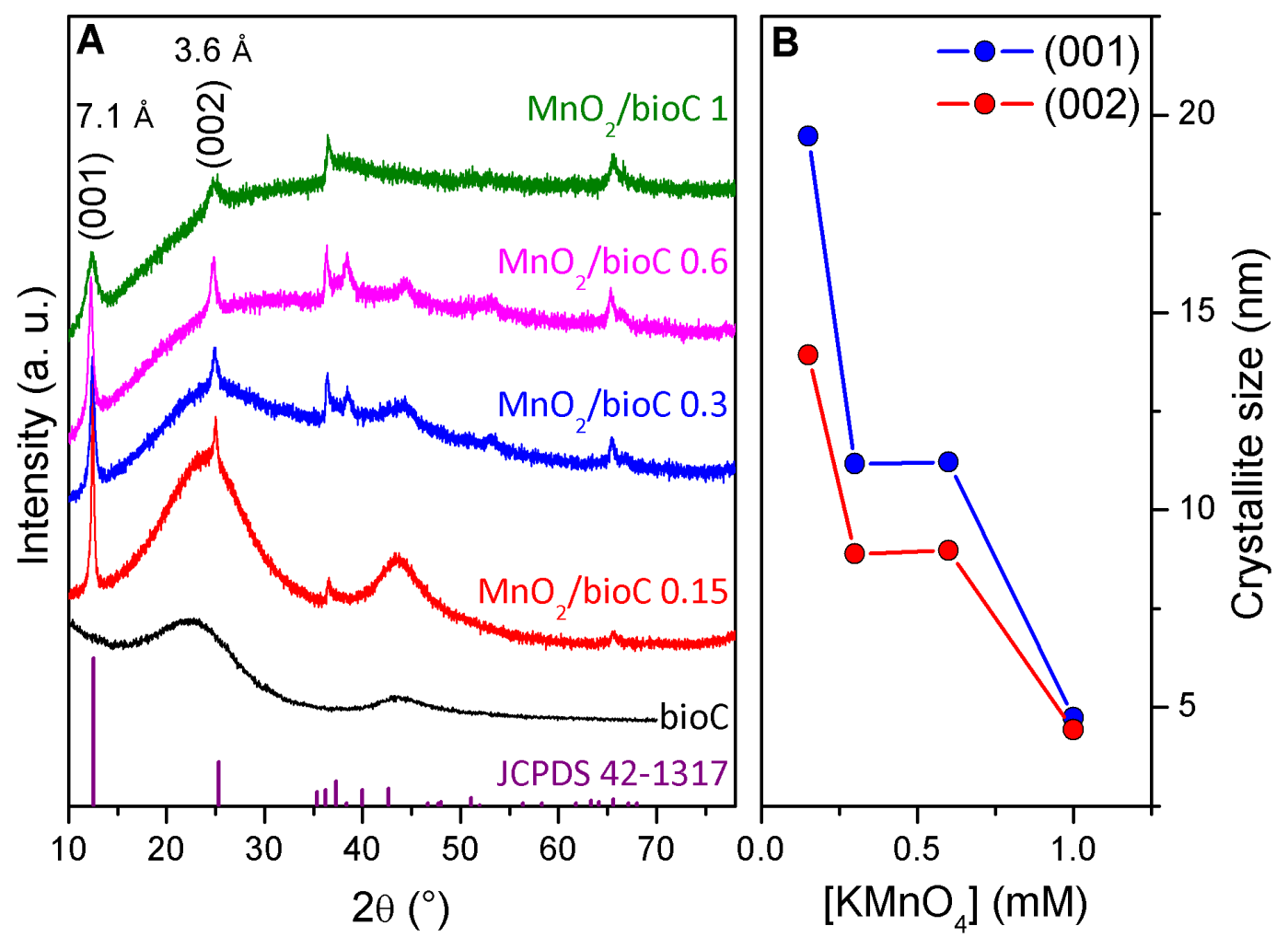

Figure 3. (A) XRD patterns of the prepared biocarbon and $\mathrm{MnO}_{2} /$ bioC materials. (B) Crystallite size for different $\mathrm{KMnO}_{4}$ concentrations determined from the integral breath of the (001) and (002) diffraction peaks using the Stokes and Wilson formula.
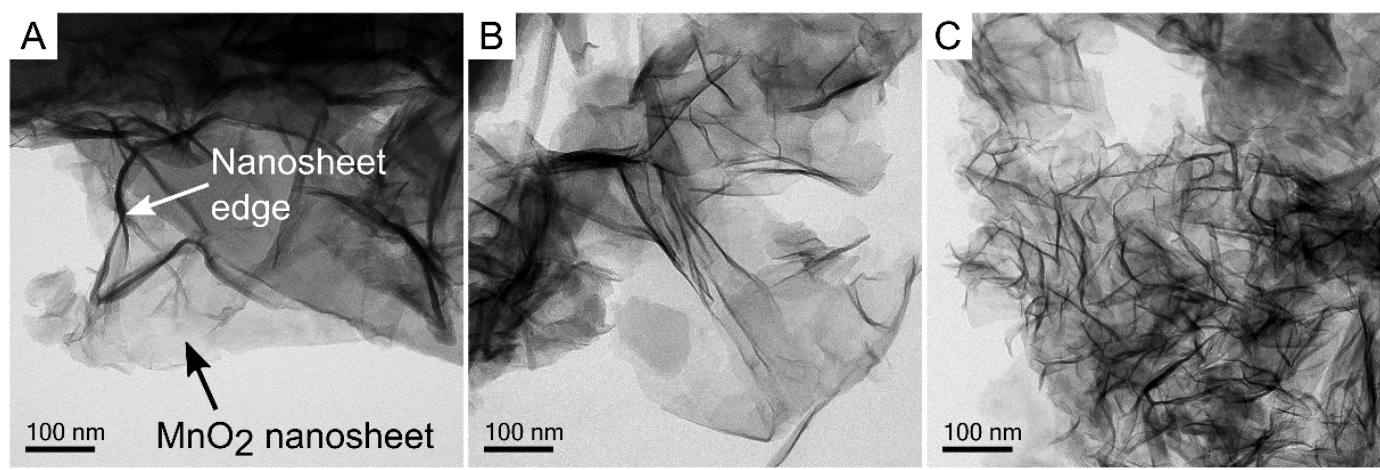

Figure 4: TEM BF images of $\mathrm{MnO}_{2}$ nanosheets obtained at different $\mathrm{KMnO}_{4}$ concentrations: (A) $0.15 \mathrm{mM}$, (B) $0.6 \mathrm{mM}$ and (C) $1 \mathrm{mM}$. 

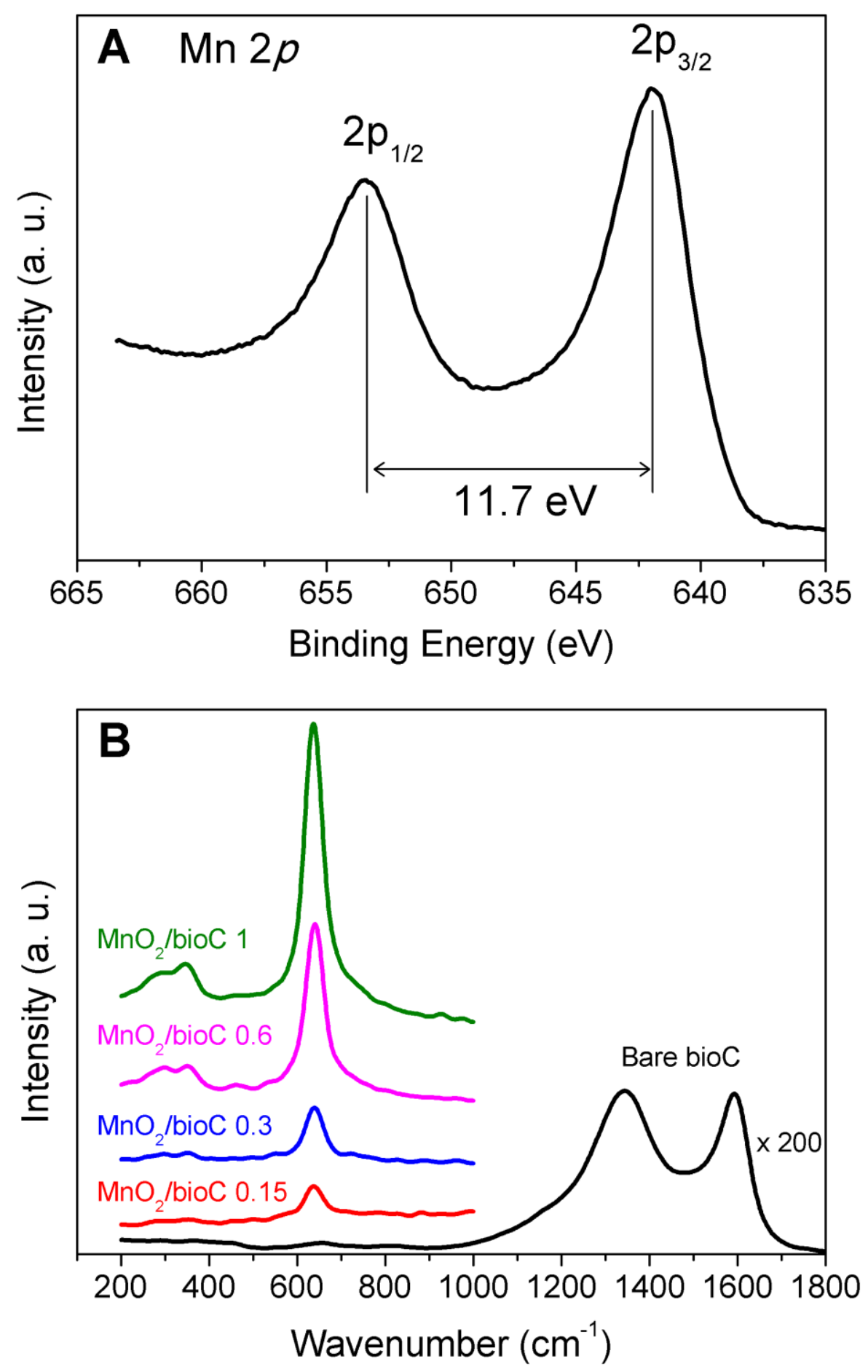

Figure 5. (A) XPS spectrum of the core-level Mn $2 p$ zone for $\mathrm{MnO}_{2} / \mathrm{bioC} 0.3 \mathrm{mM}$. (B) Raman spectra of the prepared $\mathrm{MnO}_{2} /$ bioC materials. 

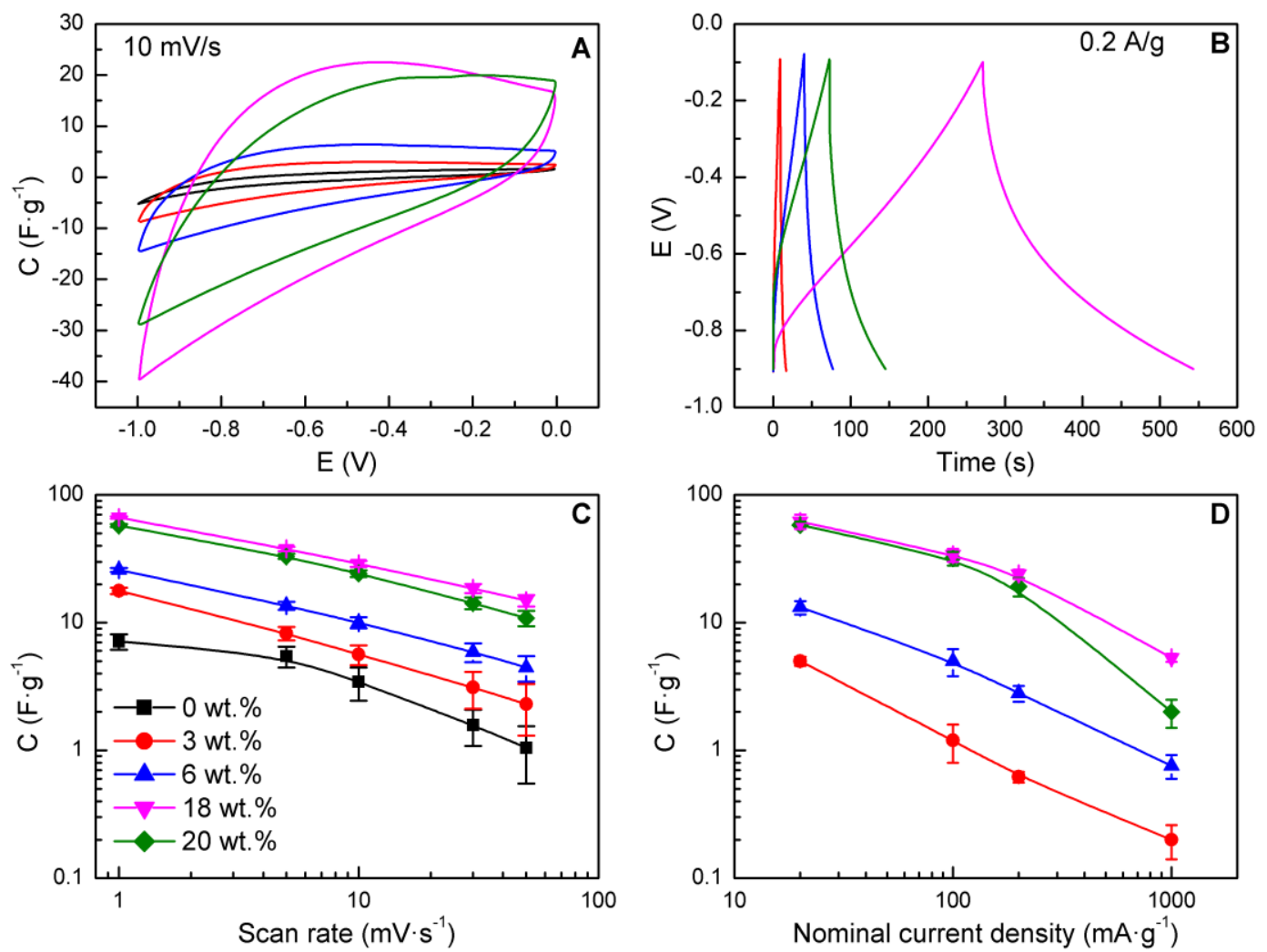

Figure 6. (A) Cyclic voltammetry curves of bare carbon electrodes as well as $\mathrm{MnO}_{2} / \mathrm{bioC}$ materials at different $\mathrm{MnO}_{2}$ contents, for a scan rate of $10 \mathrm{mV} / \mathrm{s}$. (B) Galvanostatic charge/discharge at $0.2 \mathrm{~A} / \mathrm{g}$ (calculated at total electrode mass). (C, D) Measured specific capacitances calculated at total electrode mass from cyclic voltammetry and galvanostatic charge/discharge, respectively. 

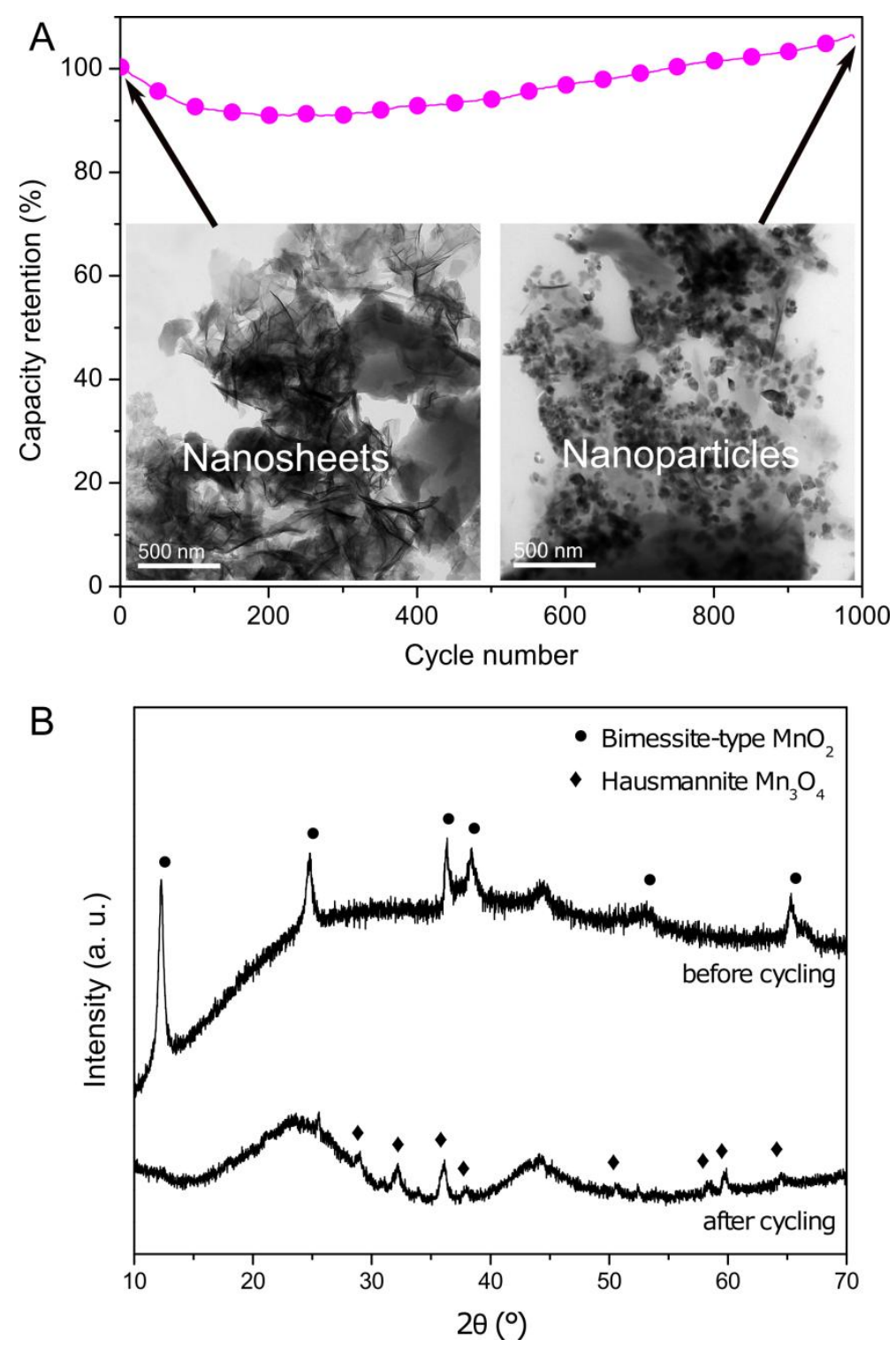

Figure 7. (A) Capacitance retention as a function of cycle number at a constant current of $0.5 \mathrm{~A} / \mathrm{g}$ in GCD measurements at total electrode mass, for a sample containing $18 \mathrm{wt}$. $\% \mathrm{MnO}_{2}$. The TEM BF in the insets show the manganese oxide morphology before and after cyclic. (B) XRD pattern recorded before and after cycling. 
Graphical abstract (TOC)
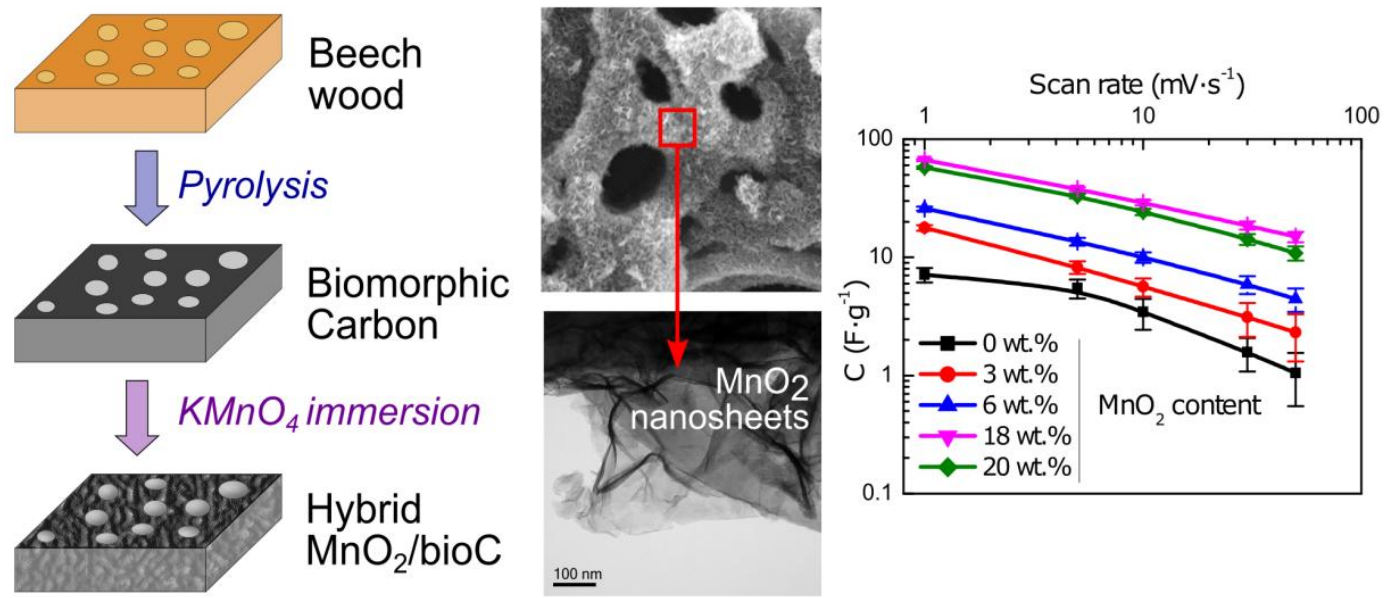